\title{
Effects of Fasting on the Hypoxia-Induced Erythropoietin Production in Rats*
}

\author{
W. Jelkmann, A. Kurtz, and C. Bauer \\ Institut für Physiologie, Universität Regensburg, Universitätsstrasse 31, D-8400 Regensburg, Federal Republic of Gerrmany
}

\begin{abstract}
In order to test the hypothesis that the early cessation of erythropoietin (Ep) production during hypobaric hypoxia is induced by lowered food intake, we have compared the plasma Ep titer of rats after exposure to continuous hypoxia ( $42.6 \mathrm{kPa} \hat{=} 7000 \mathrm{~m}$ altitude) for 4 days with that in fed or fasted rats after exposure to discontinuous hypoxia. We found that plasma Ep was rather low after 4 days of continuous hypoxia. However, the Ep titer significantly rose again, when rats were maintained normoxic for $18 \mathrm{~h}$ and then exposed to repeated hypoxia for $6 \mathrm{~h}$. Because this was also found in rats which were deprived of food during the normoxic interval and the second hypoxic period, we conclude that the fall of the Ep titer during continuous hypoxia is not primarily due to reduced food intake. In addition, our findings show that fasting per se lowers the Ep-response to hypoxia in normal rats but not exhypoxic rats.
\end{abstract}

Key words: Erythropoietin - Erythropoiesis - Hypoxia Nutrition - Rat

\section{Introduction}

Plasma erythropoietin titers first rise and then fall again during the first $12-48 \mathrm{~h}$ of acute hypoxic stress [8]. The fall appears to result from a cessation of kidney Ep production at continued hypoxia, because Ep titers in kidney tissue show the same rise and fall [8].

Dunn et al. [5] have concluded from a computer analysis of erythropoiesis that the early fall of plasma Ep might be due to a nutritional deficiency as a result of reduced food intake during continuous hypoxia. This reasoning was based on the observations that starvation can significantly reduce the Epresponse to hypoxia $[1,2,12,13]$ and that food uptake is diminished under hypoxic stress $[3,5,7]$. Furthermore, the higher Ep titer observed in plasma [14] and kidney tissue [8] of rats exposed to discontinuous instead of continuous hypoxia appeared to be in line with this interpretation, because the animals could make up for their food deficiency during the normoxic period and then be able to produce more Ep in the course of a second or third hypoxic period.

This study was done to test this hypothesis in rats. We examined whether the production of Ep during hypoxia is lowered after short periods of previous fasting. In addition, we determined plasma $E p$, body weight and food intake at exposure to continuous or discontinuous hypoxia. We also studied whether the increased plasma Ep titer following repeated hypoxia exposure is abolished when animals are deprived of food during the normoxic interval and the second

Offprint requests to: W. Jelkmann at the above address

* Supported by the Deutsche Forschungsgemeinschaft (SFB 43) hypoxic period. Our results indicate that a reduced food intake cannot account for the fall in plasma Ep during continuous hypoxia.

\section{Materials and Methods}

Male Sprague-Dawley rats $(250-285 \mathrm{~g})$ were used. Fed animals received standard diet ad libitum (Altromin 1324). All animals had free access to water. Normoxic and hypoxic rats were kept in the same room. Hypoxic animals were maintained in a hypobaric chamber at $42.6 \mathrm{kPa}$ (corresponding to $7000 \mathrm{~m}$ altitude). Effects of fasting on plasma Ep were studied after $6 \mathrm{~h}$ of hypoxia exposure in rats which had been deprived of food for either $0,18,48$, or $96 \mathrm{~h}$.

Effects of continuous hypoxia on plasma Ep, food intake and body weight were studied in fed rats for $96 \mathrm{~h}$.

Effects of discontinuous hypoxia were studied in fed and fasted rats. These animals were subjected to hypoxia for $72 \mathrm{~h}$, followed by normoxia for $18 \mathrm{~h}$, and then hypoxia for another $6 \mathrm{~h}$. Fasted rats were deprived of food during the normoxic interval and the second hypoxic period. Treatments were started at 2 p.m. except $6 \mathrm{~h}$ studies which were started $8 \mathrm{a} . \mathrm{m}$. in order to match with the beginning of the second period of hypoxia in the experiments with discontinuous hypoxia.

Plasma Ep was determined using the bioassay in exhypoxic polycythemic mice as described [9]. Ep activities were calibrated against the International Standard Preparation B.

\section{Results and Discussion}

Table 1 shows that plasma Ep titers were significantly lowered in rats which were deprived of food for just $18 \mathrm{~h}$, before they were exposed to hypoxia for $6 \mathrm{~h}$. This result complements earlier findings which demonstrate a lowered Ep-response to hypoxia after 2 or 4 days of previous fasting [1, 2, 12, 13].

Basically, the pronounced effect of fasting could be compatible with the hypothesis that reduced food intake

Table 1. Plasma Ep titers in rats exposed to $6 \mathrm{~h}$ of hypoxia at $42.6 \mathrm{kPa}$ after various periods of previous fasting

\begin{tabular}{lll}
\hline $\begin{array}{l}\text { Fasting period } \\
\text { h }\end{array}$ & $\begin{array}{l}\text { Plasma Ep titer } \\
\text { U/ml }\end{array}$ & $\begin{array}{l}\text { Number of } \\
\text { expt. }\end{array}$ \\
\hline 0 & $1.26 \pm 0.18$ & 4 \\
18 & $0.19 \pm 0.06^{*}$ & 4 \\
48 & $0.12 \pm 0.05^{*}$ & 4 \\
96 & $0.08 \pm 0.04^{*}$ & 3 \\
\hline
\end{tabular}

* Significantly different $(P<0.05)$ from 0 h (Scheffés test). Mean \pm SEM 
Table 2. Effects of continuous and discontinuous hypoxia on plasma Ep, body weight and food intake in rats

\begin{tabular}{|c|c|c|c|}
\hline Treatment & $\begin{array}{l}\text { Plasma } \\
\mathrm{U} / \mathrm{ml}\end{array}$ & $\begin{array}{l}\text { Change in body weight } \\
\%\end{array}$ & $\begin{array}{l}\text { Food intake } \\
\mathrm{g}\end{array}$ \\
\hline \multicolumn{4}{|l|}{ Normoxia $(\mathrm{N})$} \\
\hline $6 \mathrm{~h}$ & - & $-3.7 \pm 0.2$ & 0 \\
\hline $96 \mathrm{~h}$ & n.d $(<0.05)$ & $+7.6 \pm 0.5$ & $113 \pm 2$ \\
\hline \multicolumn{4}{|c|}{ Continuous hypoxia $(\mathrm{H})$} \\
\hline $6 \mathrm{~h}$ & $1.43 \pm 0.16$ & $-4.8 \pm 0.2$ & 0 \\
\hline $72 \mathrm{~h}$ & $0.24 \pm 0.09$ & $-17.6 \pm 1.1$ & $14 \pm 3$ \\
\hline $96 \mathrm{~h}$ & $0.39 \pm 0.11$ & $-21.5 \pm 1.3$ & $16 \pm 2$ \\
\hline \multicolumn{4}{|c|}{$\begin{array}{l}\text { Discontinuous hypoxia } \\
\qquad(72 \mathrm{hH}+18 \mathrm{hN}+6 \mathrm{hH})\end{array}$} \\
\hline $96 \mathrm{~h}$, fed & $1.51 \pm 0.10^{*}$ & $-13.4 \pm 1.7^{*}$ & $33 \pm 4^{*}$ \\
\hline $96 \mathrm{~h}$, fasted & $1.31 \pm 0.15^{*}$ & $-19.1 \pm 0.7$ & $14 \pm 2$ \\
\hline
\end{tabular}

Fasted animals were deprived of food during the normoxic interval and the second hypoxic period. Mean \pm SEM of 8 determinations. Statistical differences were determined only between the $96 \mathrm{~h}$ treatment

* Significantly different from $96 \mathrm{~h}$ continuous H $(P<0.05$; Scheffé's test $)$

accounts for the early fall of plasma Ep during hypoxia. Plasma Ep titers of rats exposed to continuous hypoxia were previously reported from this laboratory [8]. Plasma Ep was found to increase initially and to reach peak values $(3-4 \mathrm{U}$ $\mathrm{Ep} / \mathrm{ml})$ after $12-18 \mathrm{~h}$ at $42.6 \mathrm{kPa}$ and then to decrease again at continued hypoxia (e.g. $0.7 \mathrm{U} \mathrm{Ep} / \mathrm{ml}$ after 2 days).

However, the following studies in rats exposed to discontinuous hypoxia indicate that the early cessation of Ep production cannot simply be explained on the basis of reduced food intake during hypoxia (Table 2). We observed lowered food intake and loss of body weight in rats during 4 days of either continuous or discontinuous hypoxia. Note, however, that both fed and fasted animals had very high plasma Ep titers when they were exposed to discontinuous hypoxia. In fact, their plasma Ep titer on day 4 was not significantly different from that in rats after a single $6 \mathrm{~h}$ hypoxic period. Thus, if hypoxia preceeded fasting, it did not significantly alter the increase in plasma Ep during exposure to repeated hypoxia. The validity of this result has been based on Ep measurements in 8 separate plasma samples per treatment group (Table 2).

From Table 1, it can be seen that sufficient food intake at the onset of hypoxia is necessary for normal Ep synthesis, at least in rats. However, once the animals were exposed to hypoxia, fasting for $18 \mathrm{~h}$ did not significantly reduce the rise in plasma Ep upon a second hypoxia stress. These results make it unlike that the early fall in Ep at continuous hypoxia is caused primarily by reduced food intake as suggested [5].

The production of Ep is regulated on the basis of oxygen supply and metabolic rate of renal cells. The metabolic rate of tissues is influenced by the interaction of thyroid hormones and the adrenergic nervous system [10]. In fact, Caro et al. [2] have recently provided evidence that the effect of starvation on Ep production is mediated by the lowered activity of thyroid hormones, $T_{3}$ and $T_{4}$, at food deprivation. These authors have shown that supplementation with either $T_{3}$ or with glucose restores the Ep-response in fasted rats despite their lack of protein intake [2]. In addition, the activity of the sympathetic nervous system is reduced during starvation [10]. It is thought that catecholamines through a $\beta$-adrenergic mechanism exert an important stimulatory effect on the production of Ep [6]. Since there are also findings which indicate that rats initially respond to hypoxia with a transient increase in both thyroid function [4] and catecholamines secretion [11], the possibility subsists that these hormonal signals contribute to the change in Ep production during hypoxia exposure.

Acknowledgement. We wish to thank Miss Gisela Wischka for typing of the manuscript. Human urinary erythropoietin was kindly provided by the National Heart, Lung and Blood Institute, USA, through the courtesy of Dr. Peter P. Dukes.

\section{References}

1. Anagnostou A, Schade S, Ashkinaz M, Barone J, Fried W (1977) Effect of protein deprivation on erythropoiesis. Blood 50:10931097

2. Caro J, Silver R, Erslev AJ, Miller OP, Birgegard G (1981) Erythropoietin production in fasted rats. J Lab Clin Med 98:860868

3. Chinn KSK, Hannon JP (1969) Efficiency of food utilization at high altitude. Fed Proc 28:944-947

4. Debias DA (1966) Thyroidal-adrenal relationship in altitude tolerance. Fed Proc 25:1227-1229

5. Dunn CDR, Smith LN, Leonard JI, Andrews RB, Lange RD (1980). Animal \& computer investigations into the murine erythroid response to chronic hypoxia. Exp Hematol 8 (Suppl 8): 259-279

6. Fink GD, Fisher JW (1977) Role of the sympathetic nervous system in the control of erythropoietin production. In: Fisher JW (ed) Kidney hormones, vol II. Erythropoietin. Academic Press, New York, pp 387-413

7. Fregly MJ, Waters JW (1966) Posthypoxic drinking response of rats. Fed Proc 25:1220-1226

8. Jelkmann W (1982) Temporal pattern of erythropoietin titers in kidney tissue during hypoxic hypoxia. Pflügers Arch 393:88-91

9. Jelkmann W, Bauer C (1981) Demonstration of high levels of erythropoietin in rat kidneys following hypoxic hypoxia. Pflügers Arch 392:34-39

10. Jung RT, Shetty PS, James WPT (1980) Nutritional effects on thyroid and catecholamine metabolism. Clin Sci 58:183-191

11. Myles WS, Ducker AJ (1973) The role of the sympathetic nervous system during exposure to altitude in rats. Int J Biometeor 17:51 -58

12. Naets JP (1963) Relation between erythropoietin plasma level and oxygen requirements. Proc Soc Exp Biol Med 112:832-836

13. Reissman KR (1964) Protein metabolism and erythropoiesis. II. Erythropoietin formation and erythroid responsiveness in proteindeprived rats. Blood 23:146-153

14. Schooley JC, Mahlmann LJ (1975) Hypoxia and the initiation of erythropoietin production. Blood Cells 1:429-448

Received July 23/Accepted November 30, 1982 